\title{
Incidence of retinopathy of prematurity in multiple pregnancies conceived naturally and by assisted-reproduction techniques
}

\section{Incidencia de retinopatía del prematuro en pacientes producto de embarazos múltiples concebidos en forma natural $y$ mediante técnicas de reproducción asistida}

\section{Luis P. Orozco-Gómez*, Irving Flores-Carmona, Leonor Hernández-Salazar, Karlina Minguez-Lorenzo,} Karla I. Rojas-Morales and Juan C. Medina-Díaz

Centro Médico Nacional "20 de Noviembre", ISSSTE, Mexico City, Mexico

\begin{abstract}
Objective: To determine the incidence of retinopathy of prematurity in multiple pregnancies conceived naturally and by assisted-reproduction techniques at the Centro Médico Nacional "20 de Noviembre" del Instituto de Seguridad y Servicios Sociales de los Trabajadores del Estado, from June 2008 to June 2016. Method: Observational, comparative, descriptive and retrospective study. Group 1 consisted of children conceived by assisted-reproduction techniques and Group 2 consisted of naturally conceived children. The protocol was revised and accepted by the research ethics and biosafety committees of the Centro Médico Nacional "20 de Noviembre" with file number 497.2017. Results: One hundred and eighty-four patients were included. Group 1 consisted of 90 patients (assisted reproduction) and Group 2 consisted of 94 patients. Mean gestational age for Group 1 was 32.7 weeks \pm 2.12 weeks and for group 2 was 32.9 weeks \pm 2.17 weeks. Average weight for group 1 was 1,673 $\mathrm{g}(\sigma \mathrm{4} 425)$ and for group 2 was $1,784 \mathrm{~g}(\sigma$ 491). There were 5 patients with retinopathy of prematurity in group 1 (5/90) and 8 patients in group 2 (8/94). Conclusions: Although it is known that multiple pregnancies increase the risk of prematurity and/or low birth weight, hence increasing the probability of developing retinopathy of prematurity, this study did not find risk differences based on the type of conception for multiple pregnancies. However, a positive association was observed for multiple pregnancies of more than two fetuses and in patients with extremely low birth weight.
\end{abstract}

Key words: Assisted reproduction. Multiple pregnancy. Retinopathy of prematurity.

\section{Resumen}

Objetivo: Determinar la incidencia de la retinopatía del prematuro $(R O P)$ en productos obtenidos de embarazos múltiples concebidos de forma natural y mediante técnicas de reproducción asistida, en el Centro Médico Nacional "20 de Noviembre" del Instituto de Seguridad y Servicios Sociales de los Trabajadores del Estado, durante el periodo de junio de 2008 a junio de 2016. Método: Observacional, comparativo, descriptivo y retrospectivo. El grupo 1 constituido por niños obtenidos por técnicas de reproducción asistida, y el grupo 2 constituido por niños obtenidos por fecundación natural. El protocolo del estudio fue evaluado y aceptado por los comités de ética en investigación y bioseguridad del Centro Médico Nacional "20 de Noviembre" con número de folio 497.2017. Resultados: Se estudiaron 184 pacientes. El grupo 1 (reproducción asistida)

\section{Correspondence:}

*Luis P. Orozco-Gómez

Félix Cuevas, 540

Col. Del Valle, Del. Benito Juárez Date of reception: 08-03-2018 Mexico City, Mexico

E-mail: Iporozco@issste.gob.mx DOI: 10.24875/RMOE.M19000061
Available online: 08-05-2019 Rev Mex Oftalmol (Eng). 2019;93(3):96-102

www.rmo.com.mx license (http://creativecommons.org/licenses/by-nc-nd/4.0/). 
con 90 pacientes, el grupo 2 (fecundación natural) con 94 pacientes. La edad media gestacional para el grupo 1 fue de 32.7 semanas, con una desviación de 2.12 semanas; para el grupo 2, la edad media de gestación fue de 32.9 semanas, con una desviación de 2.17 semanas. El peso promedio del grupo 1 fue de 1,673 $\mathrm{g}(\sigma \mathrm{\sigma} 45)$ y del grupo 2 fue de 1,784 $\mathrm{g}$ ( $\sigma$ 491). En el grupo 1 se diagnosticaron 5 pacientes con ROP (5/90 5.6\%]) y en el grupo 2, 8 pacientes (8/94 8.5\%]). Conclusiones: Si bien se advierte que un embarazo múltiple incrementa la posibilidad de prematuridad y/o bajo peso al nacer y con ello mayores probabilidades de desarrollar ROP, en el estudio se observó que no existe diferencia en el riesgo relacionado con la técnica de concepción, sea reproducción asistida o fecundación natural para el embarazo múltiple. Sin embargo, sí se observó una asociación positiva para embarazos múltiples de más de dos productos y en pacientes con peso extremadamente bajo al nacer.

Palabras clave: Reproducción asistida. Embarazo múltiple. Retinopatía del prematuro.

\section{Introduction}

The incidence of multiple births has steadily increased in the last 30 years, mainly due to the increased use of assisted reproductive technologies and the increase in the average maternal age of conception. Assisted reproduction techniques are defined as any procedure that involves the manipulation of both ovules and sperm, or embryos, in order to establish a pregnancy either by gamete intrafallopian tube transfer, in vitro fertilization or intracytoplasmic sperm injection ${ }^{1}$. Multiple pregnancies are associated with a higher risk of complications compared to single pregnancies, both for the mother and the babies.

In multiple pregnancies, fetuses have a higher risk of intrauterine growth restriction. In the United Kingdom, the Fertilization and Human Embryology Authority reported that half of the twins (conceived by natural and by assisted-reproduction) are born prematurely?

In addition to the general complications of twin pregnancy per se, twin pregnancies conceived by assisted-reproduction techniques have additional risk factors, including advanced maternal age, nulliparity, use of fertility drugs and associated interventions, which may represent potential risk factors for greater perinatal morbidity ${ }^{3}$.

Retinopathy of prematurity (ROP) is an eye disease caused by an alteration of retinal vasculogenesis, which can lead to its abnormal development and total or partial visual loss, and the most important risk factor for its development is immaturity, as well as low birth weight. Other risk factors include supplemental oxygen and length of exposure to oxygen, sepsis, intraventricular hemorrhage and metabolic acidosis.

Prematurity implies a lack of development of the retinal vessels, since normal vasculogenesis begins 16 weeks after conception and reaches development at 36 weeks on the nasal side and at 40 weeks on the temporal side. Likewise, if the premature infant is exposed to high concentrations of $\mathrm{O} 2$ in early neonatal stages, the production of vascular endothelial growth factor is inhibited. As a consequence, vascular growth in the immature retina is delayed, with vascular constriction. This stops normal vascularization, with vasoconstriction and retinal ischemia. Prolonged ischemia increases the production of vascular endothelial growth factor (VEGF). In the best scenario, the area of immature retina is small, and VEGF may stimulate the growth of normal vessels in the avascular area; but if the immature area is large, VEGF will stimulate the formation of arteriovenous anastomoses at the border between the vascularized area and the non-vascularized one. Subsequently increased levels of VEGF will cause neovascularization, and vascular dilatation and tortuosity and even rubeosis iridis, with the consequences of fibrovascular proliferation, scarring and retinal detachment.

There has been speculation about the relationship between the use of assisted-reproduction techniques and the development of ROP or its severity, due to the increased incidence of prematurity and low birth weight with these techniques, and some studies have found an increased rate of visual deterioration in children with low birth weight. This study aims to review the incidence of $\mathrm{ROP}$ in preterm infants born from multiple pregnancies attended in the Centro Médico Nacional "20 de Noviembre" del Instituto de Seguridad y Servicios Sociales de los Trabajadores del Estado (ISSSTE), and its relationship with assisted-reproduction techniques.

\section{Material and methods}

A retrospective review of records of premature newborns from multiple pregnancies attended at the Centro Médico Nacional "20 de Noviembre" del ISSSTE during the period from June 2008 to June 2016 was conducted. Although the medical center is located in Mexico City, it is a tertiary referral hospital that 
Table 1. Preterm newborns from multiple pregnancies, screened for retinopathy of prematurity, according to sex, type of delivery and type of conception (Centro Nacional 20 de Noviembre, Instituto de Seguridad y Servicios Sociales para los Trabajadores del Estado, 2008-2016).

\begin{tabular}{|c|c|c|c|c|c|c|}
\hline \multirow[t]{2}{*}{ Type of conception } & \multicolumn{2}{|c|}{ Sex } & \multicolumn{3}{|c|}{ Type of delivery } & \multirow[t]{2}{*}{ Total } \\
\hline & Female & Male & Twins & Triplets & Quadruplets & \\
\hline Assisted-reproduction & 46 & 44 & 68 & 18 & 4 & 90 \\
\hline Natural conception & 54 & 40 & 80 & 14 & 0 & 94 \\
\hline Total & 100 & 84 & 148 & 22 & 4 & 184 \\
\hline
\end{tabular}

receives patients from all over the country, so the study is not limited to this city. Given that all premature babies born from multiple pregnancies are referred to the Ophthalmology Service for screening, cases of prematurity resulting from single pregnancies were not included, since they are not the intended population for this study. Full-term infants born from multiple pregnancies were not included either, since the study focuses on ROP.

The inclusion criteria were: premature newborns ${ }^{4}$, that is, age under 37 weeks of pregnancy, regardless of birth weight, born from a multiple pregnancy, attended at ISSSTE units and sent to the Ophthalmology Service of the Centro Médico Nacional "20 de Noviembre", in the period between January 2008 to June 2016, with complete medical records. Newborns who died during multiple delivery were excluded, but survivors were included in the study.

The personal data of the patients was masked to avoid their identification and thus protect their confidentiality.

From the records review the following information was obtained: type of fertilization, gestational age, type of multiple pregnancy, delivery type, birth weight, sex, newborn death, presence of ROP, stage of the disease and treatment. The population was divided into two groups. In group 1 newborns from multiple pregnancies conceived by assisted-reproduction were grouped, independently of the method used; group 2 included newborns from multiple pregnancies conceived by natural fertilization. The data obtained was registered in a format designed for that purpose. A statistical analysis of the results was performed using data description by summary measures: frequency, mode, mean, median, range, standard deviation. Likewise, and given that the study is part of the prevalence and cross-association research, statistics and tests of risk and association analysis were applied: relative risk, attributable risk and odds ratio. In cases where a frequency was zero, the corresponding correction was made with the addition of 0.5 in all frequencies. For data organization and calculation, Microsoft Excel spreadsheets (Microsoft Office) were used.

\section{Results}

Overall, 184 patients were studied. Group 1 constituted by newborns conceived by assisted-reproduction, was composed of 90 patients, of which 46 belong to the female gender and 44 to the male gender, and 68 patients were born from twin pregnancies, 18 from triplets and 4 from quadruplets. Group 2 comprised newborns conceived by natural reproduction, consisted of 94 patients, 54 females and 40 males; 80 patients in this group were twins and 14 were born from triplets (Table 1). Only one deceased newborn was excluded, born from a triplet pregnancy.

Mean gestational age for group 1 was 32.7 weeks, with a deviation of 2.12 weeks. For group 2, mean gestational age was 32.9 weeks, with a deviation of 2.17 weeks. Average weight in group 1 was $1,673 \mathrm{~g} \mathrm{( \sigma}$ $425)$ and in group 2 it was $1,784 \mathrm{~g}(\sigma 491)$. All patients from both groups were delivered by cesarean section (abdominal delivery), according to the institutional indication for multiple pregnancies. In group 1 (Table 2) 5 patients with ROP (5/90) were diagnosed, of which 1 patient had stage I, 1 stage II, 2 stage III, and 1 stage IV. Three patients of this group received treatment. One received monotherapy with an antiangiogenic intravitreal injection and the other 2 were treated by combined antiangiogenic therapy plus transpupillary laser photocoagulation.

In group 2, 8 patients had ROP. One patient had stage II, and the other 7 developed stage III. All of them received treatment, 2 of them with monotherapy with an angiogenic intravitreal injection and 6 patients were 
Table 2. Preterm newborns from multiple pregnancies, screened for retinopathy of prematurity, according to sex, type of delivery and type of conception (Centro Nacional 20 de Noviembre, Instituto de Seguridad y Servicios Sociales para los Trabajadores del Estado, 2008-2016).

\begin{tabular}{|l|c|c|c|c|c|c|}
\hline & \multicolumn{7}{|c|}{ With retinopathy of prematurity } & Without ROP \\
\cline { 2 - 7 } & Grade I & Grade II & Grade III & Grade IV & Total \\
\hline Assisted-reproduction & 1 & 1 & 2 & 1 & 5 & 85 \\
\hline Natural conception & 0 & 1 & 7 & 0 & 8 & 86 \\
\hline Total & 1 & 2 & 9 & 1 & 13 & 171 \\
\hline
\end{tabular}

ROP: retinopathy of prematurity.

Table 3. Risk analysis of assisted-reproduction and ROP

\begin{tabular}{|l|c|c|c|c|}
\hline & ROP - yes & ROP - no & Total & \\
\hline Assisted-reproduction - yes & 5 & 85 & 90 & Relative risk $=0.6527$ \\
\hline Assisted-reproduction - no & 8 & 86 & 94 & Attributable risk $=-0.0295$ \\
\hline
\end{tabular}

ROP: retinopathy of prematurity.

Table 4. Risk analysis of assisted-reproduction and ROP in preterm infants born from twins

\begin{tabular}{|l|c|c|c|l|}
\hline & ROP - yes & ROP - no & Total & \\
\hline Assisted-reproduction - yes & 4 & 64 & 68 & Relative risk $=0.5882$ \\
\hline Assisted-reproduction - no & 8 & 72 & 80 & Attributable risk $=-0.0411$ \\
\hline
\end{tabular}

ROP: retinopathy of prematurity.

treated by combined antiangiogenic therapy plus transpupillary laser photocoagulation.

No patient had serious sequelae attributed to ROP.

The risk exposure, considered in this study for assisted-reproduction as an exposure factor, was 90 patients, with a risk of 5/90. In the reference group (group 2) the risk was 8/94 (Table 3). When applying association and risk analysis, a relative risk of 0.65 was found, so we conclude that there is no association between the type of reproduction and the presence of the disease (ROP). The attributable risk analysis confirms this conclusion with a negative value $(-0.03)$, that is, the risk factor did not influence the onset of the disease. When the odds ratio was applied, a result of 0.63 was obtained, so the size of the effect also confirms the non-association of the condition with the exposure to the risk factor analyzed, with a probability of $0.39(39 \%)$ of disease occurrence in newborns conceived by assisted-reproduction (considering a $50 \%$ chance of occurrence).

An analysis of association and risk for the groups was also carried out, according to the type of delivery, of twins and of three or more newborns. No association was found for the twin delivery group (Table 4); however, a relative risk of 1.95 was found for multiple pregnancies with three or more newborns. It can be concluded that there is a positive association between assisted-reproduction and the presence of ROP, because of the greater probability of attaining multiple pregnancies of more fetuses with this technique (Table 5). In this analysis we observed that 3 of every 100 patients exposed to the risk factor would develop ROP (attributable risk of 0.03 ), with an odds ratio of 2.02 , which represents a $67 \%$ probability of developing the disease (17\% more than chance). 
Rev Mex Oftalmol (Eng). 2019;93

Table 5. Risk analysis of assisted-reproduction and ROP in preterm infants born from triplets and quadruplets

\begin{tabular}{|l|c|c|c|l|}
\hline & ROP - yes & ROP - no & Total & \\
\hline Assisted-reproduction - yes & 1.5 & 21.5 & 23 & Relative risk $=1.9565$ \\
\hline Assisted-reproduction - no & 0.5 & 14.5 & 15 & Attributable risk $=0.0318$ \\
& & $\mathrm{~N}$ & 38 & Odds ratio $=2.0232$ \\
\hline
\end{tabular}

Adjusted frequencies.

ROP: retinopathy of prematurity.

Table 6. Risk analysis of assisted-reproduction and ROP in preterm infants with low birth weight*

\begin{tabular}{|l|c|c|c|l|}
\hline & ROP - yes & ROP - no & Total & \\
\hline Assisted-reproduction - yes & 5 & 85 & 87 & Relative risk $=0.6178$ \\
\hline Assisted-reproduction - no & 8 & 78 & 86 & Attributable risk $=-0.0355$ \\
\hline
\end{tabular}

*Low birth weight $=$ less than $2,500 \mathrm{~g}$.

ROP: retinopathy of prematurity.

Table 7. Risk analysis of assisted-reproduction and ROP in preterm infants with very low birth weight*

\begin{tabular}{|l|c|c|c|l|}
\hline & ROP - yes & ROP - no & Total & \\
\hline Assisted-reproduction - yes & 5 & 28 & 33 & Relative risk $=0.5681$ \\
\hline Assisted-reproduction - no & 8 & 22 & 30 & Attributable risk $=-0.1151$ \\
\hline
\end{tabular}

*Very low birth weight $=$ less than $1,500 \mathrm{~g}$

ROP: retinopathy of prematurity.

Table 8. Risk analysis of assisted-reproduction and ROP in preterm infants with extremely low birth weight*

\begin{tabular}{|l|c|c|c|l|}
\hline & ROP - yes & ROP - no & Total & \\
\hline Assisted-reproduction - yes & 2 & 3 & 5 & Relative risk $=1.2000$ \\
\hline Assisted-reproduction - no & 1 & 2 & 3 & Attributable risk $=0.0666$ \\
& & $\mathrm{~N}$ & 8 & Odds ratio $=1.3333$ \\
\hline
\end{tabular}

*Low birth weight $=$ less than $1,000 \mathrm{~g}$.

ROP: retinopathy of prematurity.

Although birth weight was not considered an element in this study for ROP development, a risk analysis of assisted-reproduction was carried out in the groups of newborns with low birth weight (less than 2,500 g), very low birth weight (less than 1,500 g) and extremely low birth weight (less than 1,000 g). The results are presented in Tables 6, 7 and 8. No association was found in the groups of low and very low birth weight. However, there was a positive association between assisted-reproduction and
ROP development in newborns with extremely low birth weight (relative risk of 1.2), with an attributable risk of 6 in every 100 exposed patients and an odds ratio. of 1.33, that is, of a probability of occurrence of $57 \%$ ( $7 \%$ more than chance).

Considering immaturity as a causal factor of retinopathy, the risk and association of assisted-reproduction in the groups of newborns according to their gestational age was analyzed, both for very premature (28 to 
Table 9. Risk analysis of assisted-reproduction and ROP in very premature infants*

\begin{tabular}{|l|c|c|c|c|}
\hline & ROP - yes & ROP - no & Total & \\
\hline Assisted-reproduction - yes & 2 & 27 & 29 & Relative risk $=0.3448$ \\
\hline Assisted-reproduction - no & 6 & 24 & 30 & Attributable risk $=-0.1310$ \\
\hline
\end{tabular}

* Very premature infants $=28$ to 32 weeks of gestation. ROP: retinopathy of prematurity.

Table 10. Risk analysis of assisted-reproduction and ROP in extremely premature infants*

\begin{tabular}{|l|c|c|c|l|}
\hline & ROP - yes & ROP - no & Total & \\
\hline Assisted-reproduction - yes & 2.5 & 0.5 & 3 & Relative risk $=1$ \\
\hline Assisted-reproduction - no & 2.5 & 0.5 & 3 & Attributable risk $=0$ \\
\hline
\end{tabular}

*Extremely premature infants $=$ Less than 28 weeks of gestation .

Adjusted frequencies

ROP: retinopathy of prematurity.

32 weeks of gestation) and for extremely premature babies (less than 28 weeks of gestation), see Tables 9 and 10. No association was found in any of these groups, so it can be concluded that there is no additional risk related to assisted-reproduction to develop $\mathrm{ROP}$ in cases of very premature and extremely premature newborns.

\section{Discussion}

The World Health Organization refers to ROP as one of the main causes of preventable blindness worldwide, so studying the risk factors that influence its appearance is important for designing of public policies for prevention and timely detection. Its frequency is not insignificant in our setting, since the Pan-American Association of Ophthalmology considered ROP as the main cause of preventable blindness in Latin American children, responsible for approximately 25,000 cases in $2006^{5}$.

Retinal angiogenesis develops in conditions of relative hypoxia, therefore, hyperoxia is toxic to the retina, especially for immature tissues that have not yet developed their antioxidant defenses ${ }^{6}$. Thus, it is relevant to evaluate risk factors that contribute to prematurity, such as multiple pregnancies.

In Mexico, the Ministry of Health, in its clinical practice guide, and the ROP Mexico Group, as well as the Pan-American ROP screening guide, suggest screening for the following population: all preterm newborns of $\leq 34$ weeks of gestational age and/or $\leq 1,750 \mathrm{~g}$ of birth weight. Depending on the judgment of the attending physician, screening may be considered for preterm infants $>34$ weeks of gestation and weighing $>1,750 \mathrm{~g}$ who have received supplemental oxygen, and for preterm newborns who have associated risk factors ${ }^{7}$. This is relevant to analyze the association with other factors that favor these conditions, such as multiparity.

Some studies have shown that the rate of severe visual impairment is 26 times higher in newborns weighing $1,500 \mathrm{~g}$ at birth than in newborns weighing between 2,500 and 3,499 g. Newborns from multiple pregnancies have a higher rate of prematurity and low birth weight than those born from single pregnancies ${ }^{8-13}$.

In 1993, Schaffer, et al..$^{14}$ reported a relationship between ROP, low birth weight and multiple pregnancies, with a $36 \%$ lower rate in newborns from single pregnancies as opposed to newborns from multiple pregnancies.

These findings were supported by Hartikainen-Sorri, et al. ${ }^{15}$. In addition, Watts and Adams ${ }^{16}$ found that $41.6 \%$ of children conceived by in vitro fertilization progressed to stage III ROP, compared to only $9.37 \%$ of children conceived naturally.

The authors speculated that assisted-reproduction techniques represent a high proportion of ROP cases, especially of severe ROP ${ }^{17}$.

In the randomized trial of Early Treatment for ROP ${ }^{18}$, constituted by 6,998 premature babies who weighed 
$<1,251 \mathrm{~g}$ at birth, $68 \%$ had ROP. Single pregnancies represented $73 \%$ of the group with ROP, and there was no difference in ROP rates for stages I, II and III between single and multiple pregnancies. The authors concluded that the development and progression of ROP is multifactorial and probably involves factors inherent to the newborn or factors that are transmitted through the placenta before or around the time of birth $^{18}$.

Although these findings establish an important relationship between multiparity as a risk factor for the increased incidence of prematurity and, therefore, an increased risk of ROP, the association with assisted-reproduction techniques has not been very clear as a risk factor for this increased incidence.

The results of this study seek to contribute to this analysis in order to add elements to the regulation of guidelines on the number of embryos to be implanted in assisted-reproduction departments.

\section{Conclusions}

In this study, we found a $7 \%$ incidence of ROP in the examined premature newborns from multiple pregnancies, as well as an incidence of $5.5 \%$ in newborns conceived by assisted-reproduction techniques, and of $8.5 \%$ among those naturally conceived.

No positive association, relative or attributable risk, or greater chance of developing the disease was found between ROP and assisted-reproduction. We found an association between assisted reproduction as a risk factor for ROP development among newborns from multiple pregnancies with multiparity, and we also identified an increased risk for extremely low birth weight infants.

This study helps to warn that although assisted-reproduction per se is not necessarily a risk factor for the increased incidence of ROP, it can be a risk factor for newborns born from multiple pregnancies with multiparity and for newborns with an extreme low weight at birth, so a greater vigilance of preventive measures is warranted in these two cases, especially when using oxygen therapy, to prevent ROP development.

\section{Conflicts of interest}

The authors declare that they did not receive extra funding for this work.

\section{Ethical disclosures}

Protection of human and animal subjects. The authors declare that no experiments were performed on humans or animals for this study.

Confidentiality of data. The authors declare that no patient data appear in this article.

Right to privacy and informed consent. The authors declare that no patient data appear in this article.

\section{References}

1. Zuppa A, Scorrano A, Cota F, D'Andrea V, Fracchiolla A, Romagnoli C. Neonatal outcomes in triplet pregnancies: assisted reproduction versus spontaneous conception. J Perinat Med. 2007;35:339e43.

2. Human Fertilization and Embryology Authority. Multiple pregnancies and birth: considering the risks. London: HFEA; 2006.

3. Joy J, McClure I, Cooke E. A comparison of spontaneously conceived twins and twins conceived by artificial reproductive technologies. J Obstet Gynecol. 2008;28:580e5.

4. Organización Mundial de la Salud. Nota descriptiva Nacimientos Prematuros. 19 de febrero de 2018. Disponible en http://www.who.int/es/newsroom/fact-sheets/detail/preterm-birth.

5. Vásquez A. Retinopatía del prematuro, guía clínica diagnóstica-2006. Asociación Panamericana de Oftalmología.

6. Mc Leod DS, Crone SN, Lutty GA. Vasoproliferative in the neonatal dog model of oxygen-induced retinopathy. Invest Ophthalmol. Vis Sci. 1996; 37:1322-33.

7. Retinopatía del prematuro. Grupo ROP México. Disponible en: http:// www.ropmexico.org.mx/archivos/documentos/ROP_Mexico_libro.pdf.

8. Ho SK, Wu PY. Perinatal factors and neonatal morbidity in twin pregnancy. Am J Obstet Gynecol. 1975;122:979-87.

9. Hartikainen-Sorri AL, Kauppila A, Tuimala R, Kovisto M. Factors related to improved outcome for twins. Acta Obstet Gynecol Scand. 1983;62:23-5.

10. McCarthy BJ, Sachs BP, Layde PM, Burton A, Terry JS, Rochat R. The epidemiology of neonatal death in twins. Am J Obstet Gynecol. 1981; 141:252-6.

11. Nylander PP. Perinatal mortality in twins. Acta Genet Med Gemellol. 1979;28:3638

12. Zahalkova M. Perinatal and infant mortality in twins. Prog Clin Biol Res. 1978;24:115-20.

13. Luke B, Keith LG. The contribution of singletons, twins, and triplets to low birth weight, infant mortality and handicap in the United States. J Reprod Med. 1992;37:661-6.

14. Schaffer DB, Palmer EA, Plotsky DF, Metz HS, Flynn JT, Tung B, et al. Prognostic factors in the natural course of retinopathy of prematurity. Ophthalmology. 1993;100:230-7.

15. Hartikainen-Sorri AL, Kauppila A, Tuimala R, Kovisto M. Factors related to improved outcome for twins. Acta Obstet Gynecol Scand. 1983;62:23-5.

16. Watts $P$, Adams GG. In vitro fertilization and stage 3 retinopathy of prematurity. Eye. 2000;14:330-3.

17. Bergh T, Ericson A, Hillensjo T, Nygren KG, Wennerholm UB. Deliveries and children born after in-vitro fertilization in Sweden 1982-95: a retrospective cohort study. Lancet. 1999;354:1579-85.

18. Early Treatment for Retinopathy of Prematurity Cooperative Group. Revised indications for the treatment of retinopathy of prematurity. Arch Ophthalmol. 2003;121:1684-96. 